\title{
Decreased Serum Sulphydryl Levels as a Sign of Increased Oxidative Stress in Generalized Anxiety Disorder
}

\author{
Mehmet Cemal Kaya', Yasin Bez', Ibrahim Fatih Karababa², Ali Emhan², Nurten Aksoy³, \\ Mahmut Bulut ${ }^{1}$, Mehmet Gunes̨ ${ }^{1}$, Abdullah Atli ${ }^{1}$ and Salih Selek ${ }^{4} \bowtie$ \\ 1'Department of Psychiatry, Dicle University School of Medicine, Diyarbakir, Turkey \\ ${ }^{2}$ Department of Psychiatry, Harran University School of Medicine, Sanliurfa, Turkey \\ ${ }^{3}$ Department of Biochemistry, Harran University School of Medicine, Sanliurfa, Turkey \\ ${ }^{4}$ Department of Psychiatry, Istanbul Medeniyet University School of Medicine, Istanbul, Turkey
}

Objective In recent years, many published studies have focused on the relationship between oxidative stress and psychiatric disorders. However, studies in generalized anxiety disorder (GAD) are few despite relatively high prevalence rates. In an attempt to fill this gap in the literature we aimed to measure serum levels of free sulphydryl, an important member of antioxidant defense mechanisms, of the patients with GAD.

Methods A total of 35 (23 female, 12 male) GAD patients without any other co-morbid medical or psychiatric disorder and 35 ( 23 female, 12 male) healthy controls have been included in the study. Disease severity of the patients were quantified by using the Hamilton Anxiety Rating Scale (HAM-A). Serum free sulphydryl group levels of patients and healthy controls were measured in an appropriate way. Results Mean level of serum sulphydryl groups was significantly lower in the patient group. There was a negative correlation between their level and the disease duration. However, they did not show any significant correlation with the disease severity.

Conclusion Decreased serum sulphydryl level observed in pure GAD patients suggests an increased oxidative stress in these patients. Well designed future researches are needed to replicate our findings and to test the implications of the present study.

Psychiatry Investig 2013;10:281-285

Key Words Generalized anxiety disorder, Sulphydryl, Oxidative stress and antioxidant.

\section{INTRODUCTION}

Generalized anxiety disorder (GAD) is a common chronic psychiatric disorder with a lifetime prevalence rate of $5 \%$ and presents highly co-morbid to mood disorders and other anxiety disorders. ${ }^{1,2}$ Nevertheless, biochemical underpinnings and correlates of it such as status of oxidative stress parameters have not been thoroughly studied yet. ${ }^{3}$

The brain is especially vulnerable to reactive oxygen radicals because it is a highly oxygenated organ that use nearly one-fifth of the oxygen consumed by the body. ${ }^{4}$ Normally, re-

Received: October 8, 2012 Revised: January 3, 2013

Accepted: January 7, 2013 Available online: September 16, 2013

$\triangle$ Correspondence: Salih Selek, MD

Department of Psychiatry, Istanbul Medeniyet University School of Medicine, D-100 Mevkii, 34700 Kadikoy, Istanbul, Turkey

Tel: +90 (216)-280 33 33, Fax: +90 (216)-602 2805

E-mail: drselek@yahoo.com

(a) This is an Open Access article distributed under the terms of the Creative Commons Attribution Non-Commercial License (http://creativecommons.org/licenses/by$\mathrm{nc} / 3.0$ ) which permits unrestricted non-commercial use, distribution, and reproduction in any medium, provided the original work is properly cited. active oxygen radicals and antioxidant defense mechanisms maintain equilibrium in healthy individuals. Free sulphydryl groups play important roles and have well-known antioxidant activities in this equilibrium. ${ }^{5}$ They are very sensitive to oxidative damage and their levels can be accepted as a reliable indicator of oxidative stress. ${ }^{6}$ Supporting this idea, some previous studies have reported lower free sulphydryl levels in patients with various medical conditions that involve oxidation of proteins secondary to accumulation of oxidant molecules. ${ }^{7-9}$

Many recent studies in the literature have reported altered antioxidant enzyme activity in patients with various psychiatric disorders, in the form of either increment or decrement of the parameters, indicating an indirect sign of increased oxidative stress. ${ }^{10-13}$ Studies that have investigated the status of free sulphydryl groups, a well-known rapidly acting antioxidant, in psychiatric disorders are very scarce. ${ }^{14-16}$ For example, one of them has reported decreased levels of free sulphydryl groups in schizophrenia patients when compared to healthy control subjects. ${ }^{16}$ 
The status of oxidative stress and antioxidant defense mechanisms in GAD has not been focus of previous studies, yet. Thus, in an attempt to fill this gap in the literature we have decided to measure the serum levels of free sulphydryl groups in patients with GAD and compare them with those of healthy control subjects.

\section{METHODS}

\section{Study participants}

Thirty-five patients diagnosed with generalized anxiety disorder according to the DSM-IV criteria were enrolled to the study. The patients with co-morbid any other axis I and II psychiatric disorders according to DSM-IV criteria were excluded from the study. For excluding the co-morbid psychiatric conditions a detailed psychiatric interview has been conducted by using a semi-structured interview form (a form prepared by the authors according to the DSM-IV criteria outpatient survey used in previous researches of the authors before) and additionally medical records of the patients have been reviewed. In addition, pregnancy, severe systemic diseases such as renal and/or liver failure, neurological disorders such as epilepsy, diabetes mellitus, hypertension, substance use including smoking, inadequate blood sampling, severe head injury, vitamin and fish oil use were the other exclusion criteria of the study. Thus, patients with pure GAD were included in the study. Medical records of patients were overviewed and demographical and clinical characteristics such as gender, age, symptoms of GAD were recorded. Thirty-five healthy volunteers similar to the study subjects in terms of age and gender have been included in the study as the control group. Any psychiatric disorder or medical condition was ruled out from the control group by a meticulous psychiatric interview and an extensive neurological and physical examination of each healthy volunteer by the same psychiatrist (AE). The study was conducted according to the revised version of the Helsinki Declaration (Seoul 2008) and approved by the local ethics committee. All subjects were informed about the study protocol and have given their written consent.

\section{Psychiatric and biochemical measurements}

Hamilton Anxiety Rating Scale (HAM-A) was used to assess the severity of anxiety of the patients with generalized anxiety disorder. Original scale was first developed by Hamilton et al. ${ }^{17}$ in 1959 . Validity and reliability of its Turkish version was demonstrated by Yazici et al. ${ }^{18}$ in 2001 . HAM-A is composed of 14 items and provides scores between 0 and 56 . Increase in the total score reflects increased anxiety levels of the subjects. It is helpful in determining severity and symptom profile of anxiety.
Peripheral blood samples for biochemical measurement were collected from left forearm vein once into $5 \mathrm{~mL}$ vacutainer tubes at 7-8 a.m. after overnight fasting. The blood samples were centrifuged at $3000 \mathrm{rpm}$ for 10 minutes to obtain sera. Samples were stored frozen at minus $80^{\circ} \mathrm{C}$ before the analyses. The biochemical analyses were conducted at the Harran University Biochemistry Laboratory after collecting all the blood samples.

For the measurement of total free sulphydryl groups the method which was first developed by Ellman ${ }^{19}$ and later modified by $\mathrm{Hu}$ et al. ${ }^{20}$ has been used. First, $1 \mathrm{~mL}$ of buffer containing 0.1 M Tris, $10 \mathrm{mM}$ EDTA, $\mathrm{pH} 8.2$, and $50 \mu \mathrm{L}$ serums was added cuvettes, and then followed by $50 \mu \mathrm{L} 10 \mathrm{mM}$ DTNB in methanol. For each sample blanks were run as a test without DTNB in the methanol. After incubating at room temperature for 15 minutes, sample absorbance was measured at $412 \mathrm{~nm}$ on a Cecil 3000 spectrophotometer. Sample and reagent blanks were subtracted. The concentration of sulphydryl groups was calculated by using reduced glutathione as free sulphydryl group standard. Results were expressed as millimolars/liter.

\section{Procedure}

All participants gave informed consent before the study. GAD diagnosis of the patients was confirmed by using DSMIV criteria. HAM-A was performed by an experienced psychiatrist (EA) to measure anxiety levels and symptom profiles of the patients. The venous blood sampling from the patients and healthy control subjects was done only once after they gave their informed consents. Measured levels of total free sulphydryl groups of patients and healthy control subjects were compared with each other. Additionally, correlation analyses were conducted between disease duration, anxiety severity, and level of total free sulphydryl groups in the patients with GAD.

\section{Statistical analysis}

Collected data has been analyzed by using Statistical Package for Social Sciences (SPSS) version 15.0 (Chicago, IL). For the comparison of serum levels of free sulphydryl between groups the student $t$ test was used. ANOVA was applied for multiple groups and Tukey Test was used for post hoc comparisons. Categorical variables were compared between groups by using chi square test. Spearman's rank correlation coefficient $\left(\mathrm{r}_{0}\right)$ was used for the correlation analyses. Statistically significance level was accepted as $\mathrm{p}<0.05$.

\section{RESULTS}

Thirty-five patients with GAD (23 females, 12 males) and 35 
Table 1. Demographical and clinical data of patients with GAD and healthy control subjects

\begin{tabular}{|c|c|c|c|c|c|c|c|c|}
\hline \multirow{3}{*}{ Variables } & \multicolumn{3}{|c|}{ GAD patients (mean \pm SD) } & \multicolumn{3}{|c|}{ Controls $($ mean $\pm \mathrm{SD})$} & \multicolumn{2}{|c|}{ Statistics* } \\
\hline & Female & Male & Total & Female & Male & Total & & \\
\hline & $\mathrm{N}=23$ & $\mathrm{~N}=12$ & $\mathrm{~N}=35$ & $\mathrm{~N}=23$ & $\mathrm{~N}=12$ & $\mathrm{~N}=35$ & $\mathrm{t}$ & $\mathrm{p}$ \\
\hline Age (years) & $44.22 \pm 9.62$ & $37.5 \pm 15.32$ & $41.9 \pm 12.1$ & $45.57 \pm 10.13$ & $34.33 \pm 15.01$ & $41.7 \pm 12.9$ & 0.67 & 0.947 \\
\hline $\operatorname{BMI}\left(\mathrm{kg} / \mathrm{m}^{2}\right)$ & $28.4 \pm 5.38$ & $25.72 \pm 4.20$ & $27.4 \pm 5.1$ & $26.13 \pm 6.22$ & $23.41 \pm 5.1$ & $25.2 \pm 6.0$ & 1.50 & 0.137 \\
\hline HAM-A & $26.43 \pm 4.70$ & $23.42 \pm 5.00$ & $25.4 \pm 4.9$ & N/A & N/A & N/A & - & - \\
\hline Duration of illness (years) & $8.26 \pm 5.31$ & $7.58 \pm 8.34$ & $8.1 \pm 6.4$ & N/A & N/A & N/A & - & - \\
\hline Sulphydryl level (mmol/L) & $0.32 \pm 0.07^{\dagger}$ & $0.40 \pm 0.06^{\ddagger}$ & $0.34 \pm 0.07$ & $0.42 \pm 0.04$ & $0.47 \pm 0.08$ & $0.44 \pm 0.06$ & 5.89 & $<0.001$ \\
\hline
\end{tabular}

*shows comparison of patient with GAD and healthy control subjects, ${ }^{\dagger}$ significantly lower than that of male patients with GAD ( $\mathrm{p}=0.001$ ) and female healthy control subjects $(\mathrm{p}<0.001)$, ${ }^{\ddagger}$ significantly lower than that of male healthy control subjects $(\mathrm{p}=0.037)$. GAD: generalized anxiety disorder, SD: standard deviation, $t$ : $t$ value calculated by student $t$ test, BMI: body mass index, HAM-A: Hamilton Anxiety Rating Scale, N/A: not applicable

healthy control subjects (23 females, 12 males) were enrolled in the study. Mean age, BMI, and gender distribution of the patients and control subjects are given in Table 1. There was no significant difference between groups in terms of age and BMI. Serum total free sulphydryl levels of both groups are also shown in Table 1. Mean serum total free sulphydryl level of the patients was lower than that of control subjects ( $\mathrm{p}<$ 0.001). During enrollment, 12 of the patients were taking a serotonin-noradrenalin reuptake inhibitor (SNRI) and 15 of them were on a selective serotonin reuptake inhibitor (SSRI) for their treatment, whereas, 8 patients were drug-naive. There was no statistically significant difference among SNRI, SSRI and drug-naive groups in terms of serum total free sulphydryl groups level $(\mathrm{F}=0.71, \mathrm{p}=0.664)$. In the patient group, there was no statistically significant correlation between total HAM-A scores and sulphydryl levels in the patient group $\left(\mathrm{r}_{0}=\right.$ $-0,126, p=0.487, n=35$ ). There were no statistically significant correlations between HAM-A sub scores and the serum parameter as well. On the other hand, a negative correlation was observed between disease duration and sulphydryl levels $\left(\mathrm{r}_{0}=-0.487, \mathrm{p}=0.003, \mathrm{n}=35\right)$ (Figure 1).

Further analyses of our data have yielded an effect of gender. Mean sulphydryl level of women with GAD was lower than that of male GAD patients, and then both male and female control subjects, as well $(\mathrm{F}=21.69, \mathrm{df}=3, \mathrm{p}<0.001)$. Mean age of both genders were statistically similar in both groups. Additionally, in the patient group severity of anxiety determined by HAM-A scores were similar in both genders (Table 1).

\section{DISCUSSION}

In the present study, serum sulphydryl levels of the GAD patients were found to be lower than healthy control subjects. It was negatively correlated with the disease duration in the patient group. On the other hand, there was no correlation between serum sulphydryl level and the disease severity as

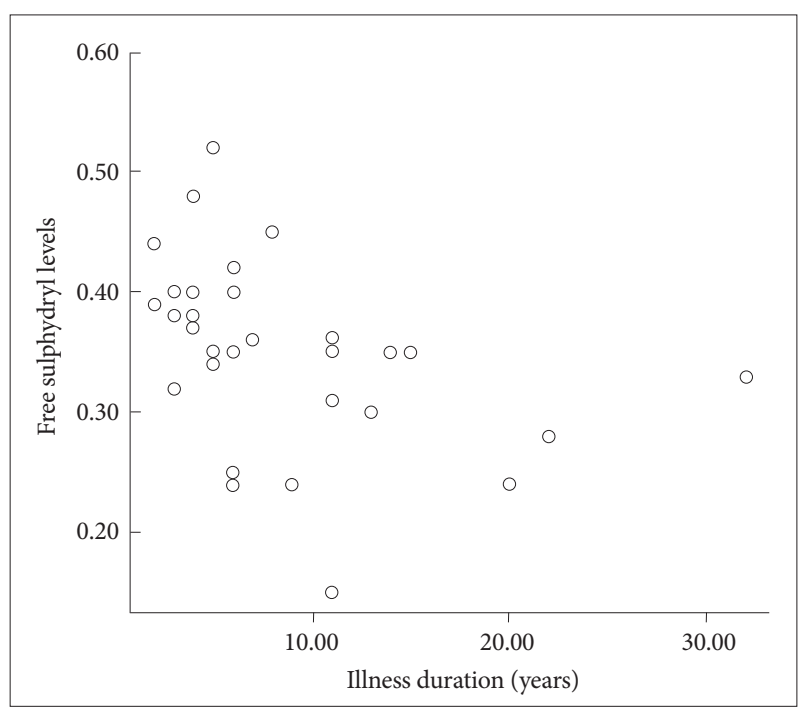

Figure 1. Scatterplot of illness duration and the serum parameter in patient group.

determined by HAM-A. To the best of our knowledge, this is the first study that investigated serum levels of sulphydryl groups, an important indicator of oxidative stress, in patients with GAD.

To date, serum sulphydryl levels have not been studied in patients with any Axis-I psychiatric diagnosis other than schizophrenia and panic disorder. Furthermore, GAD is one of those psychiatric disorders; even oxidant or antioxidant parameters of those patients with it have not been investigated yet.

Two previous studies published recently have shown lower serum free sulphydryl levels in patients with schizophrenia when compared to healthy control subjects..$^{15,21}$ Lower levels of sulphydryl observed in the present study support the idea that sulphydryl, as an important antioxidant, may be an underlying factor in the pathophysiology of psychiatric disorders. Role of oxidative mechanisms has been previously studied in many anxiety disorders other than GAD. ${ }^{22-25}$ Those studies 
have consistently concluded an imbalance of the oxidative mechanisms. In another study, conducted by Ersoy et al. ${ }^{14}$ besides oxidative/antioxidative parameters sulphydryl groups were also measured in patients with panic disorder. That study has reported a negative correlation between sulphydryl levels and disease duration. It is similar to the finding of the present study which suggests a lower sulphydryl level by increasing disease duration in patients with GAD. This finding suggests decreased antioxidant capacity as the disease progresses. On the other hand, our findings did not support any correlation between sulphydryl levels and disease severity. We are unable to compare this finding with the current literature since no study including the one conducted by Ersoy et al. had tested it. However, an indirect support to our finding comes from the study published by Herken et al. ${ }^{26}$ that has reported no significant association between disease severity and oxidative parameters in their patients with panic disorder, an anxiety disorder.

Decrease in serum sulphydryl level, an antioxidant, may reflect a decreased total antioxidant capacity. In a previous study, decreased total antioxidant capacity has been reported in anxious women when compared to non-anxious women. ${ }^{27} \mathrm{Al}-$ though their finding can be interpreted only for female gender, our findings support the idea that antioxidant capacity of anxious males may also be diminished given the similarity of gender distribution of our patient and control groups. GAD tends to be a chronic disorder with waxing and waning of the symptoms. Disability associated with GAD is known to be greater in women than in men. ${ }^{28}$ Therefore, lower sulphydryl levels in female patients may be related with the greater disability previously reported in female GAD patients. Further studies are welcomed to clarify the gender difference of $\mathrm{SH}$ levels in GAD.

In recent years, $\mathrm{N}$-acetylcysteine (NAC) has been used in various psychiatric disorders and has been a promising molecule for augmenting the treatment effect in those disorders. ${ }^{29-31}$ Its mechanism of action against reactive oxygen radicals and oxidants may be modulated by sulphydryl groups since NAC is a well-known resource of them. ${ }^{32,33}$ Thus, one may think that GAD patients may also benefit from augmentation with NAC treatment. Although, our study provides very preliminary and indirect evidence for its use in GAD treatment, it is obvious that future placebo controlled randomized studies are needed to test its beneficial effects.

The present study has some limitations: small sample size, cross-sectional design, and ongoing antidepressant treatments. However, the levels of free sulphydryl groups did not show any significant difference across the treatment groups and drugnaive patients. On the other hand, enrollment of pure GAD patients in the present study may serve as a strong aspect of it since $\mathrm{GAD}$ is a psychiatric disorder with high co-morbidity rates.

In conclusion, this is the first study showing decreased serum free sulphydryl groups in GAD patients which suggest an imbalance of oxidative mechanisms and also providing some preliminary evidence that ascribe a possible role to the sulphydryl groups in its pathophysiology. Future studies including measurement of sulphydryl groups are needed to elucidate the exact nature of their role in the pathophysiology of anxiety disorders, namely GAD.

\section{REFERENCES}

1. Wittchen HU. Generalized anxiety disorder: prevalence, burden, and cost to society. Depress Anxiety 2002;16:162-171.

2. Kessler RC, Keller MB, Wittchen HU. The epidemiology of generalized anxiety disorder. Psychiatr Clin North Am 2001;24:19-39.

3. Dugas MJ. Generalized anxiety disorder publications: so where do we stand? J Anxiety Disord 2000;14:31-40.

4. Halliwell B. Oxidants and the central nervous system: some fundamental questions. Is oxidant damage relevant to Parkinson's disease, Alzheimer's disease, traumatic injury or stroke? Acta Neurol Scand Suppl 1989;126:23-33.

5. Yardim-Akaydin S, Ozkan Y, Ozkan E, Torun M, Simşek B. The role of plasma thiol compounds and antioxidant vitamins in patients with cardiovascular diseases. Clin Chim Acta 2003;338:99-105.

6. Hu ML. Measurement of protein thiol groups and glutathione in plasma. Methods Enzymol 1994;233:380-385.

7. Lorber A, Pearson CM, Meredith WL, Gantz-Mandell LE. Serum sulfhydryl determinations and significance in connective tissue diseases. Ann Intern Med 1964;61:423-434.

8. Collier A, Wilson R, Bradley H, Thomson JA, Small M. Free radical activity in type 2 diabetes. Diabet Med 1990;7:27-30.

9. Kadota K, Yui Y, Hattori R, Murohara Y, Kawai C. Decreased sulfhydryl groups of serum albumin in coronary artery disease. Jpn Circ J 1991;55: 937-941.

10. Yao JK, Reddy R, McElhinny LG, van Kammen DP. Reduced status of plasma total antioxidant capacity in schizophrenia. Schizophr Res 1998; 32:1-8.

11. Selek S, Herken H, Bulut M, Ceylan MF, Celik H, Savas HA, et al. Oxidative imbalance in obsessive compulsive disorder patients: a total evaluation of oxidant-antioxidant status. Prog Neuropsychopharmacol Biol Psychiatry 2008;32:487-491.

12. Selek S, Altindag A, Saracoglu G, Celik H, Aksoy N. Prolidase activity and its diagnostic performance in bipolar disorder. J Affect Disord 2011;129:84-86.

13. Selek S, Bulut M, Ocak AR, Kalenderoğlu A, Savaş HA. Evaluation of total oxidative status in adult attention deficit hyperactivity disorder and its diagnostic implications. J Psychiatr Res 2012;46:451-455.

14. Ersoy MA, Selek S, Celik H, Erel O, Kaya MC, Savas HA, et al. Role of oxidative and antioxidative parameters in etiopathogenesis and prognosis of panic disorder. Int J Neurosci 2008;118:1025-1037.

15. Dietrich-Muszalska A, Olas B, Głowacki R, Bald E. Oxidative/nitrative modifications of plasma proteins and thiols from patients with schizophrenia. Neuropsychobiology 2009;59:1-7.

16. Huang TL, Liou CW, Lin TK. Serum thiobarbituric acid-reactive substances and free thiol levels in schizophrenia patients: effects of antipsychotic drugs. Psychiatry Res 2010;177:18-21.

17. Hamilton M. The assessment of anxiety states by rating. Br J Med Psychol 1959;32:50-55.

18. Yazıcı MK, Demir B, Tanriverdi N, Karaağaoğlu E, Yolaç P. Hamilton anxiety rating scale: interrater reliabilty and validity study. Turk Psiki- 
yatri Derg 1998;9:114-117.

19. Ellman GL. Tissue sulfhydryl groups. Arch Biochem Biophys 1959; 82:70-77.

20. Hu ML, Louie S, Cross CE, Motchnik P, Halliwell B. Antioxidant protection against hypochlorous acid in human plasma. J Lab Clin Med 1993;121:257-262.

21. Huang TL, Liou CW, Lin TK. Serum thiobarbituric acid-reactive substances and free thiol levels in schizophrenia patients: effects of antipsychotic drugs. Psychiatry Res 2010;177:18-21.

22. Chakraborty S, Singh OP, Dasgupta A, Mandal N, Nath Das H. Correlation between lipid peroxidation-induced TBARS level and disease severity in obsessive-compulsive disorder. Prog Neuropsychopharmacol Biol Psychiatry 2009;33:363-366.

23. Tezcan E, Atmaca M, Kuloglu M, Ustundag B. Free radicals in patients with post-traumatic stress disorder. Eur Arch Psychiatry Clin Neurosci 2003;253:89-91.

24. Atmaca M, Kuloglu M, Tezcan E, Ustundag B. Antioxidant enzyme and malondialdehyde levels in patients with social phobia. Psychiatry Res 2008;159:95-100.

25. Kuloglu M, Atmaca M, Tezcan E, Ustundag B, Bulut S. Antioxidant enzyme and malondialdehyde levels in patients with panic disorder. Neuropsychobiology 2002;46:186-189.

26. Herken H, Akyol O, Yilmaz HR, Tutkun H, Savas HA, Ozen ME, et al. Nitric oxide, adenosine deaminase, xanthine oxidase and superoxide dismutase in patients with panic disorder: alterations by antidepressant treatment. Hum Psychopharmacol 2006;21:53-59.

27. Arranz L, Guayerbas N, De la Fuente M. Impairment of several immune functions in anxious women. J Psychosom Res 2007;62:1-8.

28. Vesga-López O, Schneier FR, Wang S, Heimberg RG, Liu SM, Hasin DS, et al. Gender differences in generalized anxiety disorder: results from the National Epidemiologic Survey on Alcohol and Related Conditions (NESARC). J Clin Psychiatry 2008;69:1606-1616.

29. Bulut M, Savas HA, Altindag A, Virit O, Dalkilic A. Beneficial effects of $\mathrm{N}$-acetylcysteine in treatment resistant schizophrenia. World J Biol Psychiatry 2009;10:626-628.

30. Lavoie S, Murray MM, Deppen P, Knyazeva MG, Berk M, Boulat O, et al. Glutathione precursor, $\mathrm{N}$-acetyl-cysteine, improves mismatch negativity in schizophrenia patients. Neuropsychopharmacology 2008;33: 2187-2199.

31. Berk M, Copolov DL, Dean O, Lu K, Jeavons S, Schapkaitz I, et al. Nacetyl cysteine for depressive symptoms in bipolar disorder--a doubleblind randomized placebo-controlled trial. Biol Psychiatry 2008;64: 468-475.

32. Forman MB, Puett DW, Cates CU, McCroskey DE, Beckman JK, Greene HL, et al. Glutathione redox pathway and reperfusion injury. Effect of $\mathrm{N}$-acetylcysteine on infarct size and ventricular function. Circulation 1988;78:202-213.

33. Sochman J, Kolc J, Vrána M, Fabián J. Cardioprotective effects of N-acetylcysteine: the reduction in the extent of infarction and occurrence of reperfusion arrhythmias in the dog. Int J Cardiol 1990;28:191-196. 